
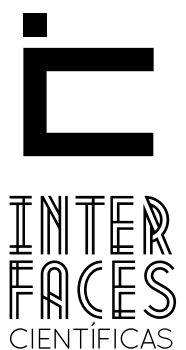

DIREITO

\title{
PODER CONSTITUINTE DERIVADO DECORRENTE DOS MUNICÍPIOS?
}

Cristiane Vitório de Souza ${ }^{1}$

\section{RESUMO}

O objetivo deste artigo é discutir a existência no ordenamento jurídico brasileiro de um poder constituinte derivado decorrente dos Municípios. Utilizando o método qualitativo e as técnicas da pesquisa documental e bibliográfica, apresenta o conceito de poder constituinte originário e poder constituinte derivado decorrente. Em seguida, discorre sobre o poder constituinte derivado decorrente dos Estados-Membros e do Distrito Federal e contrapõe as visões majoritária e minoritária sobre a possibilidade de existência do poder constituinte derivado decorrente dos Municípios. Por fim, questiona os argumentos utilizados por quem não reconhece esse poder e à luz dos princípios federativos e da simetria conclui que o poder constituinte derivado decorrente dos Municípios decorre do poder constituinte originário.

\section{PALAVRAS-CHAVE}

Poder constituinte derivado decorrente dos Municípios. Princípio Federativo. Princípio da Simetria.

\section{Ana Luzia Santos ${ }^{2}$}

\section{ABSTRACT}

The objective of this article is to discuss the existence in the Brazilian legal system of a constituent power related to the legislation of the Municipalities. Using the qualitative method and the techniques of documentary and bibliographic research, the concepts of original constituent power and secondary constituent power are presented. Then, the constituent secondary power from the Member States and the Federal District are discussed, opposing to the majority and minority visions about the possibility of the existence of the constituent secondary power from the Municipalities. In the end, there is a questioning about the arguments used by those who do not recognize this power, and, using the federative principle and the principle of symmetry, it may be possible to conclude that the constituent secondary power from the Municipalities derives from the original constituent power.

\section{KEYWORDS}

Constituent secondary power from the Municipalities. Federative Principle. Principle of Symmetry. 


\section{RESUMEN}

El objetivo de este artículo es explicar la existencia en el ordenamiento jurídico brasileño de un poder constituyente derivado decurrente de los Municipios. Utilizando el método cualitativo y las técnicas de investigación documental y bibliográfica, presenta el concepto del poder constituyente originario y poder constituyente derivado decurrente. A continuación, se analiza el poder constituyente derivado decurrente de los Estados Miembros y en el Distrito Federal y contrapone las visiones mayoritaria y minoritaria sobre la posibilidad de la existencia del poder constituyente

\section{INTRODUÇ̄̃̃O}

O objetivo desse artigo é discutir a existência de um poder constituinte derivado decorrente dos Municípios. Paulo Bonavides (2011) afirma que o poder constituinte diz respeito ao fenômeno político que disciplina a organização de uma sociedade. Para facilitar o estudo acerca do poder constituinte existente nas sociedades contemporâneas surgiu uma divisão doutrinária e jurisprudencial, que distingue poder constituinte originário e poder constituinte derivado. 0 originário é inicial, permanente, autônomo e incondicionado. Já o derivado é secundário, temporário, dependente, condicionado e limitado.

Na Constituição da República Federativa do Brasil, elaborada através do poder constituinte originário e promulgada em 1988, o poder constituinte derivado decorrente foi atribuído a todos os entes federativos. No entanto, a doutrina constitucionalista majoritária e a jurisprudência do Supremo Tribunal Federal (STF), em princípio, entenderam que o poder constituinte derivado decorrente deveria ser atribuído apenas aos Estados-membros da federação brasileira, mas, posteriormente, o STF admitiu também a existência de um poder constituinte derivado decorrente do Distrito Federal. legislación secundaria de los Municipios. Al final, se cuestionan los argumentos utilizados por quienes no reconocen este poder $y$, utilizando los principios federativo y de simetría, concluye que el poder constituyente derivado decurrente los Municipios se deriva del poder constituyente originario.

\section{PALABRAS CLAVE}

Poder constituyente legislación secundaria de los Municipios. Principio federativo. Principio de simetría.

Este artigo vai além desse entendimento, apresentando argumentos relevantes que atestam a existência de um poder constituinte derivado decorrente dos Municípios. Ao considerar a existência do poder constituinte derivado decorrente dos Municípios, dá uma relevante contribuição para o avanço da ciência jurídica, especialmente ao Direito Constitucional, trazendo a possibilidade de novas discussões acerca de uma temática que ainda é muito carente de análise.

Este artigo trabalha com a hipótese de que é possível afirmar a existência de um poder constituinte derivado decorrente dos Municípios que decorre do princípio federativo e do princípio da simetria. Para comprovar essa hipótese, utilizou-se como fontes: a doutrina, a jurisprudência e as normas constitucionais. Tais fontes foram analisadas mediante o método qualitativo, assentado em uma análise principiológica, e em técnicas de pesquisa documental e bibliográfica. 


\section{PODER CONSTITUINTE DERIVADO DECORRENTE DOS ESTADOS-MEMBROS}

0 poder constituinte derivado decorrente dos Estados decorre essencialmente do princípio federativo, segundo o qual os Estados-membros, assim como os demais entes federativos, gozam de autonomia. A Constituição da República Federativa do Brasil, de 1988, atribuiu aos Estados-membros a capacidade de autogoverno, de autodeterminação, de auto-organização e de autolegislação (CUNHA JÚNIOR, 2012). Aqui interessa principalmente as duas últimas competências, pois elas possibilitam que os Estados federados elaborem e promulguem suas próprias Constituições Estaduais, por meio de seus próprios poderes legislativos.

É válido ressaltar que, por possuir um poder constituinte constituído pela Constituição Federal, como observou Paulo Bonavides (2011), a autonomia dos Estados possui diversas limitações materiais. Esses limites estão prescritos nos artigos 25, 22, parágrafo único, 23 e 24 da Carta Magna. 0 artigo 25 dispõe que os Estados ao produzir suas normas devem respeitar os princípios da Lei Maior. 0 artigo 22 enumera as competências privativas da União, trazendo em seu parágrafo único a possibilidade de autorizar os Estados a legislar sobre questões específicas das matérias reservadas à União. 0 artigo 23 trata das competências comuns de todos os entes da federação - União, Estados, Distrito Federal e Municípios. 0 artigo 24 disciplina as competências concorrentes da União, dos Estados e do Distrito Federal (BRASIL, 2011). Desses dispositivos constitucionais, decorre o entendimento doutrinário de que as competências exclusivas reservadas aos Estados foram bastante limitadas. Os doutrinadores também apresentam posição pacífica ao afirmar que os Estados têm competência legislativa residual, ou seja, para identificá-las se faz necessário excluir aquelas que foram destinadas exclusivamente à União e aos Municípios. Vale res- saltar que essa distribuição de competências não fere o princípio federativo, pois, a Constituição Federal não estabelece uma hierarquia interna entre os entes da federação brasileira, afinal, por se tratar de um Estado Federado, o Brasil não é formado por entes soberanos. A soberania pertence à nação (CUNHA JÚNIOR, 2012).

Além dos limites materiais acima referidos, o poder constituinte decorrente derivado também está sujeito a limites formais, uma vez que, mesmo sendo o Poder Legislativo Estadual unicameral, devem os Estados observar os requisitos básicos do processo legislativo federal, que se apresentam como normas de observância obrigatória para a elaboração das Constituições Estaduais (BRASIL, 2011). É válido salientar que essa determinação constitucional não implica uma subordinação dos Estados-membros à União, mas, se fundamenta no princípio da supremacia da Constituição Federal, que foi elaborada pelo poder constituinte originário e que constituiu os poderes legislativos dos demais entes federativos (CUNHA JÚNIOR, 2011).

Não há dúvida de que existe um poder derivado decorrente conferido pelo poder originário constituinte aos Estados-membros. Porém, sempre existiu controvérsia doutrinária e jurisprudencial acerca da existência do poder constituinte derivado decorrente do Distrito Federal, e, sobretudo, dos Municípios. 


\section{PODER CONSTITUINTE DERIVADO DECORRENTE NO DISTRITO FEDERAL}

Desde a promulgação da Constituição da República Federativa do Brasil, em 1988, a doutrina e a jurisprudência negaram a existência de um poder derivado decorrente do Distrito Federal. Apoiavam-se no fato de que o artigo 32, caput, estabelece que este ente federativo deve ser organizado mediante uma Lei Orgânica e não uma Constituição e que a referida lei seria materialmente distinta da constituição, além de subordinar-se à Constituição Federal e à Constituição Estadual.

Pedro Lenza (2008), na obra Direito Constitucional Esquematizado, afirmava que o Distrito Federal não possuía poder derivado decorrente porque é regido por Lei Orgânica, que não possui nada parecido com uma Constituição.

No entanto, atualmente, tanto os doutrinadores quanto os membros do Poder Judiciário, consideram que o Distrito Federal, em virtude do princípio federativo, que conferiu autonomia aos entes da federação, possui poder constituinte derivado decorrente e que a Lei Orgânica Distrital tem natureza material constitucional, sendo efetivamente uma Constituição Distrital, podendo, inclusive, ser submetida ao controle de constitucionalidade concentrado perante o Tribunal de Justiça do Distrito Federal.

O próprio Pedro Lenza (2011), a partir da $13^{a}$ edição da obra mencionada, mudou a posição firmada nas edições anteriores:

verifica-se a manifestação do poder constituinte derivado decorrente, qual seja, a competência que o DF tem para elaborar a sua lei orgânica (verdadeira Constituição Distrital), sujeitando-se aos mesmos limites já apontados para os Estados-membros e, assim, aplicando-se por analogia, o artigo 11 do ADCT. (LENZA, 2011, p. 181)
Dirley da Cunha Júnior (2012) considera que existe um poder constituinte decorrente do Distrito Federal, não obstante a Constituição Federal referir-se à sua organização por meio de Lei Orgânica. Chegou a essa conclusão porque a esse ente da federação foram atribuídas competências reservadas aos Estados, o que evidenciaria a vontade do constituinte de nivelar os dois entes; e porque a Lei Orgânica do Distrito Federal possui natureza material de Constituição, submetendo-se apenas à Constituição Federal.

Dirley da Cunha Júnior e Marcelo Novelino (2011) reiteram essa visão ao afirmarem que a Lei Orgânica do Distrito Federal pode ser considerada, apesar da denominação adotada pelo legislador constituinte, uma verdadeira Constituição Distrital e ao reconhecerem que no caso de violação desse documento legislativo por lei ou ato normativo do Distrito Federal, admite-se o controle de constitucionalidade concentrado pelo Tribunal de Justiça do Distrito Federal.

Dirley da Cunha Júnior (2011) afirma que compete aos Tribunais de Justiça dos Estados e do Distrito Federal, processar e julgar Ação Direta de Inconstitucionalidade, Ação Direta de Inconstitucionalidade por Omissão, Ação Declaratória de Constitucionalidade e Arguição de Descumprimento de Preceitos Fundamentais, tomando como parâmetro a Constituição Estadual e a Lei Orgânica do Distrito Federal.

O Supremo Tribunal Federal reconheceu a Lei Orgânica do Distrito Federal como Constituição. É o que se infere do relato do Ministro Celso de Mello, no julgamento de uma Reclamação contra decisão do Tribunal de Justiça do Distrito Federal:

A Lei Orgânica do Distrito Federal constitui instrumento normativo primário destinado a regular, de modo subordinante - e com inegável primazia sobre o ordenamento positivo distrital - a vida jurídico-administra- 
tiva e político-institucional dessa entidade integrante da federação brasileira. Este ato representa, dentro do sistema de direito positivo, o momento inaugural e fundante da ordem jurídica vigente no âmbito do Dis-

\section{PODER CONSTITUINTE DERIVADO DECORRENTE NOS MUNICÍPIOS: DIVERGÊNCIA DOUTRINÁRIA}

Após certa relutância, foi reconhecido o poder constituinte derivado decorrente do Distrito Federal. No entanto, ainda pairam muitas controvérsias acerca da existência de um poder constituinte derivado decorrente dos Municípios. Embora, predomine a visão de que esse poder não pode ser estendido aos referidos entes.

Pedro Lenza (2011) compreende que os Municípios, por força dos artigos $1^{\circ}$ e 18 da Constituição Federal, fazem parte da federação brasileira e são, portanto, autônomos em relação aos outros entes, uma vez que também possuem autonomia administrativa, financeira e política. Considera também que o artigo 29 da Carta Magna delimita sua capacidade de auto-organização, cujo exercício foi estabelecido pelo parágrafo único do artigo 11, do ADCT, que dispõe caber à Câmara Municipal a elaboração da Lei Orgânica Municipal, a qual deve respeitar a Constituição Federal e a Constituição Estadual. Desse modo, a Lei Orgânica estaria submetida a dois graus de imposição legislativa constitucional. Essa constatação o fez concluir que o poder constituinte decorrente conferido aos Estados-membros não foi estendido aos Municípios.

\section{Conforme Pedro Lenza,}

0 poder constituinte derivado decorrente é apenas o poder que os Estados-membros, por meio das Assembleias Legislativas, têm de elaborar as Constituições Estaduais, bem como o DF, por meio da Câmara Legislativa, de elaborar a sua Lei Orgânica, devendo, ambas, obedecer aos limites impostos pela Constituição Fede- trito Federal. Em uma palavra: a Lei Orgânica equivale, em força, autoridade e eficácia jurídicas, a um verdadeiro estatuto constitucional, essencialmente equiparável às Constituições promulgadas pelos Estados-membros (BRASIL apud CUNHA JÚNIOR, 2012). ral, nos exatos termos do artigo 25, caput. e artigo 32, caput. da CF/88. Essa particularidade, portanto, não se estende aos Municípios e Territórios Federais que eventualmente venham ser criados, pelas razões acima expostas (LENZA, 2011, p. 182).

Segundo Noêmia Porto, o poder constituinte derivado decorrente deve ser de segundo grau, isto é, encontrar sua fonte de legitimidade direta na Constituição Federal. Desta forma, os Estados-membros teriam poder constituinte derivado decorrente, uma vez que precisam respeitar apenas a Constituição Federal. Já os Municípios não teriam esse poder, porque as Leis Orgânicas Municipais devem respeitar a Constituição Federal e a Constituição Estadual. Para a doutrinadora, não basta ser membro da federação para ter poder constituído derivado decorrente, é necessário que o poder de auto-organização decorra diretamente do poder constituinte originário. Acrescenta ainda, que ato legal contrariado em face de Lei Orgânica municipal enseja controle de legalidade e não controle de constitucionalidade (PORTO apud LENZA, 2011).

Entendimento semelhante é defendido por Luiz Alberto David Araújo e Vidal Serrano Nunes Júnior (2011). Esses autores afirmam, em síntese, que a simples leitura do artigo 29, da Lei Maior, permitiria afastar a existência de poder constituinte decorrente em relação aos Municípios, seja porque estes não são regidos por constituições, e sim por Leis Orgânicas, seja porque estas devem submissão não só à Constituição Federal, mas também à Constituição do Estado. Eis a conclusão dos autores sobre o tema: 
Enquanto aos Estados foi conferida organização por Constituições, aos Municípios cogitou-se de leis orgânicas, as quais, de sua vez, deveriam guardar fidelidade não só à Constituição da República, mas também à respectiva Constituição do Estado, revelando-se assim que o mais alto documento normativo municipal não adviria de um Poder Constituinte, mas de mero órgão legislativo: a Câmara dos Vereadores (ARAÚJO E NUNES JÚNIOR, 2011, p. 333)

Para o doutrinador Dirley da Cunha Júnior (2012), o poder constituinte decorrente só pode ser exercido por Estados-membros e pelo Distrito Federal e não pelos Municípios, porque as Leis Orgânicas Municipais se subordinam à Constituição Estadual e à Constituição Federal. Na sua perspectiva, "falar de um poder constituinte decorrente dos Municípios é cogitar da existência de um poder decorrente de poder decorrente" (CUNHA JÚNIOR, 2012).

Enquanto Pedro Lenza, Noêmia Porto, Luiz Alberto David Araújo, Vidal Serrano Nunes Júnior e Dirley da Cunha Júnior rejeitam a existência do poder constituinte derivado decorrente dos Municípios, Sérgio Resende Barros e José Luiz Quadros de Magalhães o defendem.

Sérgio Resende Barros (2012) considera que a primeira Constituição da República, inspirada no modelo norte-americano, instituiu uma federação composta por Estados-membros e pelo Distrito Federal, ignorando os Municípios. Porém, a presente Constituição estabeleceu que fazem parte da federação, além dos Estados-Membros e do Distrito Federal, os Municípios. Este federalismo seria um federalismo trino, porque haveria três níveis de poder governamental, e seria distinto do federalismo norte-americano, no qual não há esse terceiro nível. Considera que apesar das vozes contrárias, reconhecer o federalismo trino leva à dedução de que além do poder constituinte derivado decorrente estadual, existe um poder constituinte derivado decorrente municipal. Também, pensa que embora a Constituição denomine o estatuto jurídico do Município de Lei Orgânica, ele é verdadeiramente uma Constituição Municipal, que sucede à estadual, que por sua vez sucede à federal.

José Luiz Quadros de Magalhães (2012) acredita que tanto os Estados-membros quanto os Municípios possuem poder constituinte derivado decorrente. Porém, o poder dos Estados-membros seria de segundo grau porque a Constituição Estadual deve respeitar a Constituição Federal e o poder dos Municípios seria de terceiro grau, porque a Lei Orgânica Municipal deve respeitar tanto a Constituição Federal quanto a Constituição Estadual. Mas, ressalta que ambos os poderes são subordinados à vontade do poder constituinte originário.

\section{ANÁLISE DO PODER CONSTITUINTE DERIVADO DECORRENTE DOS MUNICÍPIOS À LUZ DOS PRIN- CÍPIOS FEDERATIVO E DA SIMETRIA}

A Constituição da República dos Estados Unidos do Brasil, promulgada em 1891, estabeleceu como forma de estado o federalismo. As constituições seguintes a mantiveram, inclusive a Constituição da República Federativa do Brasil, de 1988, nos artigos $1^{\circ}$ e 18 :

Art. $1^{\circ} \mathrm{A}$ República Federativa do Brasil, formada pela união indissolúvel dos Estados e Municípios e do Distrito Federal, constitui-se em Estado Democrático de Direito.

Art. 18. A organização político-administrativa da República Federativa do Brasil compreende a União, os Estados, o Distrito Federal e os Municí- 
pios, todos autônomos, nos termos desta Constituição (BRASIL, 2011).

Não obstante a clareza do constituinte originário ao estabelecer que são entes federativos à União, os Estado-membros, o Distrito Federal e os Municípios, ainda há quem relute em reconhecer o caráter de ente federativo dos Municípios. É o caso do eminente constitucionalista José Afonso da Silva (2011). Em algumas passagens de sua obra, reconhece que a Constituição integrou os Municípios na estrutura federativa, atendendo ao apelo de municipalistas como Hely Lopes Meirelles e Diogo Lordello de Melo, que há muito defendiam a inserção dos Municípios na federação brasileira. Desse modo, José Afonso da Silva constata: “Nos termos, pois, da Constituição, o Município brasileiro é entidade estatal integrante da Federação, como entidade político-administrativa e financeira” (SILVA, 2011, p. 639).

Porém, em outros momentos expõe visão diversa sobre o tema. Pede vênia àqueles que pensam de modo contrário, mas considera que a tese de que os Municípios devem realmente integrar a federação é equivocada, pois, compreende que não é porque uma entidade tenha autonomia territorial e autonomia político-institucional, que necessariamente integre 0 conceito de entidade federativa. Considera que existe federação de estados e não de municípios. Argumenta ainda que a própria Constituição em alguns artigos, como o $18, \$ 4^{\circ}$ e o 35 , mantém os Municípios como divisões dos Estados ao afirmar que a criação, incorporação, fusão e desmembramento de Municípios, e a intervenção deverão ser realizadas pelos Estados.

0 argumento do ilustre doutrinador não se sustenta porque a Carta Magna, no artigo $18, \S 3^{\circ}$, confere ao Congresso Nacional a competência para convocar o plebiscito e editar lei complementar para criação, incorporação, fusão e desmembramento dos Estados, e determina no artigo 34 que, excepcionalmente, cabe à União intervir nos Estados. Desse modo, se considerarmos verdadeira a tese de que pelas razões apontadas os Municípios são meras divisões dos Estados, também teremos que considerar que os Estados são meras divisões da União, implodindo o pacto federativo, que inclusive é cláusula pétrea no nosso ordenamento.

Divergindo substancialmente do referido doutrinador, Paulo Bonavides (2011) considera:

\begin{abstract}
as prescrições do novo estatuto fundamental de 1988 a respeito da autonomia municipal configuram indubitavelmente o mais considerável avanço de proteção e abrangência já recebido por esse instituto em todas as épocas constitucionais de nossa história. Com efeito, as mudanças havidas, alargaram o raio de autonomia municipal no quadro da organização política do país, dando-lhe um alcance e profundidade que o faz indissociável da essência do próprio sistema federativo, cujo exame, análise e interpretação já não podem levar a cabo com indiferença à consideração da natureza e, sobretudo, da dimensão trilateral do novo modelo de federação introduzido no país por obra da Carta Constitucional de 5 de outubro de 1988 (BONAVIDES, 2011, p. 344).
\end{abstract}

O mesmo doutrinador considera que as competências legislativas e administrativas conferidas aos Municípios, espancam dúvidas que pairavam na doutrina e na jurisprudência acerca da autonomia municipal. A Constituição Federal estabelece nos artigos 23, 29 e 30 a capacidade de auto-organização dos Municípios. 0 artigo 29 estabelece os preceitos básicos que devem constar na lei orgânica. 0 artigo 23 fixa as competências comuns de todos os entes federativos. 0 artigo 30, I, dispõe que os Municípios possuem competência legislativa geral para tratar de assuntos de interesse local. 0 artigo 30, II, fixa a competência legislativa suplementar desses entes federativos e o artigo 30, III a IX, estabelece a competência administrativa (BONAVIDES, 2011).

Tomando como base o texto constitucional e as palavras de Paulo Bonavides, é indubitável a existência em nosso sistema jurídico do princípio federativo. Para Dirley da Cunha Júnior (2012), este princípio define a forma de estado que se constitui a partir de uma união indissolúvel de organizações políticas autôno- 
mas, instituída por uma constituição rígida, com o fim de criar o Estado Federal. Os entes federativos, sem perderem suas personalidades jurídicas, abdicam de algumas prerrogativas em benefício do Estado Federal, entre elas está a soberania. A ideia de federação relaciona-se: à noção de território, que é o limite dentro do qual o Estado exerce soberanamente o poder de império; e à ideia de descentralização política, que consiste na concessão pela Constituição Federal aos entes federativos da capacidade de auto-organização, de produção de normas sobre assuntos de sua competência. De acordo com o autor, "podemos dizer que, no Estado Federal, há um governo central e vários governos locais, todos exercendo, em condições de igualdade e com fundamento na Constituição, o poder político". (CUNHA JÚNIOR, 2012, p. 536-537).

0 constituinte originário concedeu aos entes federados o poder constituinte derivado decorrente. Conforme explicitado nas seções anteriores deste artigo, não há questionamento acerca da existência de poder constituinte derivado decorrente dos Estados. Porém, os doutrinadores e a jurisprudência não reconheceram imediatamente a existência de poder derivado decorrente do Distrito Federal nem dos Municípios. Atualmente, o poder constituinte derivado decorrente do Distrito Federal é ponto pacífico na doutrina e na jurisprudência do Supremo Tribunal Federal, mas, esse reconhecimento ainda não foi estendido pela maioria aos Municípios.

Luiz Alberto David Araújo e Vidal Serrano Nunes Júnior (2011) afirmam que não pode ser reconhecido o poder constituinte derivado decorrente dos Municípios, porque a Lei Fundamental incumbiu os referidos entes de elaborarem leis orgânicas e não constituições. Todavia, esse posicionamento destoa do entendimento majoritário da doutrina e da jurisprudência que declaram que a Lei Orgânica do Distrito Federal equivale a uma Constituição. A mesma compreensão pode ser estendida à Lei Orgânica dos Municípios, pois os artigos 29 e 32, estabelecem que os estatutos jurídicos dos dois entes devem seguir idêntico procedimento:
Art. 29. O Município reger-se-á por lei orgânica, votada em dois turnos, com o interstício mínimo de dez dias, e aprovada por dois terços dos membros da Câmara Municipal, que a promulgará, atendidos os princípios estabelecidos nesta Constituição, na Constituição do respectivo Estado e os seguintes preceitos: [...]

Art. 32. O Distrito Federal, vedada sua divisão em Municípios, reger-se-á por lei orgânica, votada em dois turnos com interstício mínimo de dez dias, e aprovada por dois terços da Câmara Legislativa, que a promulgará, atendidos os princípios estabelecidos nesta Constituição. (BRASIL, 2011)

Aqueles que reconhecem o poder constituinte derivado decorrente do Distrito Federal, argumentam que a $L e$ Orgânica Distrital assemelha-se materialmente à Constituição Estadual, porque a Constituição Federal atribuiu-lhe competências típicas dos Estados. Dirley da Cunha Júnior, por exemplo, afirma que essa circunstância revela a vontade do constituinte de equipará-los. Esta tese não subsiste a um exame mais acurado, pois, o constituinte originário também atribuiu ao Distrito Federal competências específicas dos Municípios. Utilizando tal argumento, poder-se-ia afirmar que o constituinte originário também quis equiparar o Distrito Federal aos Municípios. $E$, ainda é importante lembrar que o Distrito Federal é parcialmente tutelado pela União, uma vez que as Polícias Civil e Militar e o Corpo de Bombeiros Militar estão sob a responsabilidade deste ente federativo, conforme dispõe o artigo $32, \S^{\circ}$ da Constituição Federal (BRASIL, 2011).

Pedro Lenza, Noêmia Porto, Luiz Alberto David Araújo e Vidal Serrano Nunes Júnior argumentam que os Municípios não possuem poder constituinte derivado decorrente, porque este só se configura quando decorre diretamente da Lei Maior. Consideram que só existe poder constituinte derivado decorrente de segundo grau. José Luiz Quadros de Magalhães, que defende a existência do poder constituinte derivado decorrente dos Municípios, considera-o de terceiro grau, porque a Lei Orgânica teria que respeitar tanto a Constituição Federal quanto a Constituição Estadual.

Data máxima vênia, os argumentos utilizados pelos doutrinadores não procedem, pois, foi o poder cons- 
tituinte originário que instituiu o poder constituinte derivado decorrente tanto dos Estados-membros e do Distrito Federal quanto dos Municípios. Outrossim, a observância de normas da Constituição Federal e da Constituição Estadual não decorre de uma subordinação, mas do princípio da simetria.

Conforme Marcelo Novelino, "a simetria impõe a adoção, pela Constituição dos Estados-membros e pela Lei Orgânica dos Municípios, de certos paradigmas traçados pela Constituição da República" (NOVELINO, 2011, p. 77).

Dessa forma, as leis orgânicas devem respeitar preceitos das cartas políticas federal e estaduais devido a um limite imposto pelo constituinte originário, e não porque o poder de auto-organização dos Municípios seja derivado dos Estados.

\section{CONSIDERACÕ̃ES FINAIS}

Nesse artigo evidenciou-se que não pairam dúvidas sobre a existência do poder constituinte derivado decorrente dos Estados-Membros e, atualmente, sobre a do poder constituinte derivado decorrente do Distrito Federal. Porém, há controvérsia doutrinária e jurisprudencial acerca da existência desse poder no âmbito dos Municípios.

A maioria da doutrina nega que esses entes tenham esse poder, porque são regidos por Lei Orgânica e não por Constituição, e por considerarem que a Lei Orgânica Municipal deve respeitar tanto a Constituição Federal quanto a Constituição Estadual, estando submetida a dois graus de imposição legislativa constitucional. A minoria da doutrina, que reconhece a existência do poder constituinte derivado decorrente dos Municípios, considera que a Lei Orgânica é, na verdade, uma Constituição Municipal, e defende que o poder dos Municípios é de terceiro grau, porque a Lei Orgânica Municipal deve respeitar a Constituição Federal e a Constituição Estadual,
Tendo em vista o princípio da simetria, caso algum ente federativo, Estado-Membro, Distrito Federal ou Município, não observe as normas de reprodução obrigatória da Carta Magna, manifesta-se a inconstitucionalidade que deve ser examinada em sede de controle de constitucionalidade, concentrado perante o Supremo Tribunal Federal. Se o Município não respeitar às normas de reprodução obrigatória da Constituição Estadual, cabe representação de inconstitucionalidade pela via concentrada no Tribunal de Justiça do Estado. Se leis e atos normativos municipais não respeitarem à $L e i$ Orgânica, seria o caso dos legisladores refletirem sobre a possibilidade de admitir o controle de constitucionalidade pelo Tribunal de Justiça do Estado, utilizando como parâmetro a Lei Orgânica, uma vez que o poder constituinte originário não criou Poder Judiciário municipal.

embora ressaltem que ambos os poderes subordinam-se à vontade do poder constituinte originário.

Todavia, esse estudo demonstrou que uma análise da Constituição Federal, realizada à luz do princípio federativo e do princípio da simetria, impõe o reconhecimento da existência do poder constituinte derivado decorrente dos Municípios, mas, em outros termos. 0 federalismo brasileiro é distinto do federalismo adotado em outros Estados, pois aqui se reconhece os Municípios como entes federativos autônomos, política, administrativa e financeiramente. A Constituição Federal atribuiu a todos os entes federativos o poder de auto-organização. Nesse sentido, a Lei Orgânica Municipal é uma Constituição Municipal e o poder constituinte derivado decorrente dos Municípios deriva do poder constituinte originário, e não do poder constituinte derivado decorrente dos Estados-Membros, como defendem a doutrina majoritária e a minoritária, portanto, não há que se falar em poder 
de terceiro grau. Pensar de modo diferente equivale a desrespeitar o princípio federativo, que é um princípio fundamental, protegido por cláusula pétrea.

Além disso, o respeito que a Lei Orgânica Municipal deve guardar em relação à Constituição Federal e à Constituição Estadual decorre do princípio da simetria, um limite que foi imposto pelo constituinte originário aos Estados-Membros, Distrito Federal e Municípios, e não porque o poder de auto-organização dos Municípios seja derivado dos Estados.

\section{REFERÊNCIAS}

ARAÚJO, Luiz Alberto David de NUNES JÚNIOR, Vidal Serrano. 15. ed. Curso de Direito Constitucional. São Paulo: Saraiva, 2011.

BARROS, Sérgio Resende de. Noções sobre o poder constituinte. Disponível em: http://www.srbarros. com.br/pt/nocoes-sobre-poder-constituinte.cont. Acesso em: 23 abr. 2012.

BRASIL. Constituição da República Federativa do Brasil. 45. ed. São Paulo: Saraiva, 2011. (Coleção Saraiva de Legislação)

BRASIL. Supremo Tribunal Federal. RCL 3436/ DF. Apud. CUNHA JÚNIOR, Dirley. Curso de Direito Constitucional. 6. ed. Salvador: Juspodium, 2012, p. 263 [nota de rodapé].

BONAVIDES, Paulo. Curso de Direito Constitucional. 26. ed. São Paulo: Malheiros, 2011.

CUNHA JÚNIOR, Dirley da. Controle de Constitucionalidade. Teoria e Prática. 5 ed. Salvador: Juspodium, 2011.

CUNHA JÚNIOR. Dirley da. Curso de Direito Constitucional. 6. ed. Salvador: Juspodium, 2012.

CUNHA JÚNIOR. Dirley da e NOVELINO, Marcelo. Constituição Federal para concursos. 2. ed. Salvador: Juspodium, 2011.

\section{LENZA, Pedro. Direito Constitucional Esquematiza-}

do. 12. ed. São Paulo: Saraiva, 2008.

\section{LENZA, Pedro. Direito Constitucional Esquematiza-}

do. 15. ed. São Paulo: Saraiva, 2011.

MAGALHÃES, José Luiz Quadros de. 0 poder constituinte decorrente. Disponível em: http://www.egov. ufsc.br/portal/sites/default/files/anexos/1494414945-1-PB.html. Acesso em: 23 abr. 2012.

NOVELINO, Marcelo. Direito Constitucional. 5. ed. Rio de Janeiro: Forense; São Paulo: Método, 2011.

SILVA, José Afonso da. Curso de Direito Constitucional Positivo. 34. ed. São Paulo: Malheiros, 2011.

1 Mestre em Educação pela Universidade Federal de Sergipe Professora da Secretaria de Educação do Estado de Sergipe e da Secretaria Municipal de Educação do Município de Aracaju e graduanda em Direito pela Universidade Tiradentes. Participa do Grupo de Estudos e Pesquisas em História da Educação da UFS e do Grupo de Pesquisa História das Práticas Educacionais da UNIT. cristianevitorio@hotmail.com

2 Mestre em Educação pela Universidade Federal de Sergipe (2006). Professora Titular - Secretaria Estadual de Educação e Desportos do Estado de Sergipe, graduanda em Direito pela Universidade Tiradentes. analuzsan5@hotmail.com 